\title{
Spatial patterns of North Atlantic Oscillation influence on mass balance variability of European glaciers
}

\author{
B. Marzeion ${ }^{1}$ and A. Nesje ${ }^{2}$ \\ ${ }^{1}$ Center of Climate and Cryosphere, University of Innsbruck, Innsbruck, Austria \\ ${ }^{2}$ Bjerknes Centre for Climate Research, and Department of Earth Science, University of Bergen, Bergen, Norway
}

Correspondence to: B. Marzeion (ben.marzeion@uibk.ac.at)

Received: 18 November 2011 - Published in The Cryosphere Discuss.: 3 January 2012

Revised: 5 April 2012 - Accepted: 18 May 2012 - Published: 14 June 2012

\begin{abstract}
We present and validate a set of minimal models of glacier mass balance variability. The most skillful model is then applied to reconstruct 7735 individual time series of mass balance variability for all glaciers in the European Alps and Scandinavia. Subsequently, we investigate the influence of atmospheric variability associated with the North Atlantic Oscillation (NAO) on the glaciers' mass balances.

We find a spatial coherence in the glaciers' sensitivity to NAO forcing which is caused by regionally similar mechanisms relating the NAO forcing to the mass balance: in southwestern Scandinavia, winter precipitation causes a correlation of mass balances with the NAO. In northern Scandinavia, temperature anomalies outside the core winter season cause an anti-correlation between NAO and mass balances. In the western Alps, both temperature and winter precipitation anomalies lead to a weak anti-correlation of mass balances with the NAO, while in the eastern Alps, the influences of winter precipitation and temperature anomalies tend to cancel each other, and only on the southern side a slight anti-correlation of mass balances with the NAO prevails.
\end{abstract}

\section{Introduction}

The North Atlantic Oscillation (NAO) is the most prominent mode of atmospheric variability over the North Atlantic Ocean and Northwestern Europe (Visbeck et al., 2001; Wanner et al., 2001; Hurrell et al., 2003). One measure of the state of the NAO is the NAO index, calculated as the difference in sea-level pressure between Stykkisholmur, Iceland and Ponta Delgada, Azores (Hurrell, 1995b). The impact of NAO variability is most pronounced during the winter months and strongest over western Norway (Nesje et al., 2000). During the positive phase, i.e., stronger than normal pressure gradient between Iceland and Azores, stronger than normal westerlies, above normal precipitation and mild temperatures prevail across the eastern North Atlantic and northwestern Europe. During pronounced negative phases of the NAO, opposite patterns of temperature and precipitation anomalies are observed (see Hurrell, 1995a; Wanner et al., 2001; Hurrell et al., 2003, for an overview over the NAO and its influence on European climate).

By influencing precipitation and temperature anomalies, the NAO also exerts control over glacier mass balances. Pohjola and Rogers (1997) find that positive mass balances of Scandinavian glaciers during the 80 s and 90 s were caused by strong westerlies over the northeastern Atlantic, which are linked to the NAO. Reichert et al. (2001) find that for Nigardsbreen, an eastern outlet glacier from the Jostedalsbreen ice cap, the impact of winter precipitation overrules the impact of positive temperature anomalies, leading to a correlation of mass balance and NAO. Nesje et al. (2000) show that the control of the NAO over the glacier mass balance in Scandinavia gradually decreases with increasing continentality (i.e., towards the east), and Rasmussen and Conway (2005) find correlations between the Arctic Oscillation and mass balances of 12 Scandinavian glaciers to be stronger than between NAO and mass balances.

In the European Alps, the relation between climate anomalies originating from the Atlantic and glacier mass balance is more complex, as the Alps are situated in the transition zone between northern Europe, experiencing warm and wet conditions during positive phases of the NAO, and southern Europe, experiencing drier than normal conditions, and 
only small temperature deviations (Wanner et al., 2001). The influence of the NAO in the Alps is, therefore, generally less pronounced than in Scandinavia (Six et al., 2001) and more ambiguous (Scherrer et al., 2004). Huss et al. (2010) find a rather strong influence of the (longer term) Atlantic Multidecadal Oscillation on mass balances of glaciers in the Swiss Alps. Using a coupled general circulation model to drive a glacier mass balance model, Reichert et al. (2001) find that the mass balance of Rhonegletscher in the Western Alps is more sensitive to precipitation than temperature anomalies, resulting in an anti-correlation of the mass balance with the NAO. However, Steiner et al. (2008) show that winter precipitation is less important for length variations of Alpine glaciers than for Norwegian glaciers. Moreover, Marzeion et al. (2012) present a reconstruction of mass balances anomalies of glaciers in the European Alps based on a simple model derived from monthly values of temperature and precipitation and a set of mass balance measurements needed both to train and to validated the mass balance model, and they find that glaciers (especially in the central and eastern) Alps are more sensitive to temperature anomalies than to precipitation anomalies.

As input, Marzeion et al. (2012) use the HISTALP dataset (Auer et al., 2007) ${ }^{1}$, which provides monthly precipitation sums and $2 \mathrm{~m}$ temperatures on a $5 \times 5 \mathrm{~min}$ grid of the greater alpine region, covering the years 1780 to 2008 (temperature) and 1801 to 2003 (precipitation), and area-integrated mass balances obtained from Cogley $(2009)^{2}$. Here, we first transfer their modeling approach from the HISTALP data to CRU TS 3.0 data (Mitchell and Jones, 2005) ${ }^{3}$ in Sect. 2.1. As in Marzeion et al. (2012), in the following we refer to this model as the individually trained model and to the model using the mean parameters of the individually trained model the mean model (see below for a detailed description). In Sect. 2.2, we present another model of the glacier mass balance, which is based solely on climatological values of precipitation and temperature data as input, and does not depend on measured mass balances for training, but only for validation. In the following, we refer to this model as the climatologically derived model. A detailed validation of the models is presented together in Sect. 2.3. We then apply the models to all European glaciers contained in the extended format of the World Glacier Inventory (WGI-XF) data base (Cogley, $2005^{2}$, based on WGMS and NSIDC, 1989) and perform a correlation-based analysis of the response of the glaciers' mass balances to NAO-related variability in temperature and precipitation (see Fig. 1 for an overview of the spatial distribution of all glaciers considered in this study). The results are shown in Sect. 3, and we discuss them and conclude in Sect. 4.

\footnotetext{
1 available at http://www.zamg.ac.at/histalp

2 available at http://people.trentu.ca/ $\sim$ gcogley/glaciology/

3 available at http://badc.nerc.ac.uk/
}

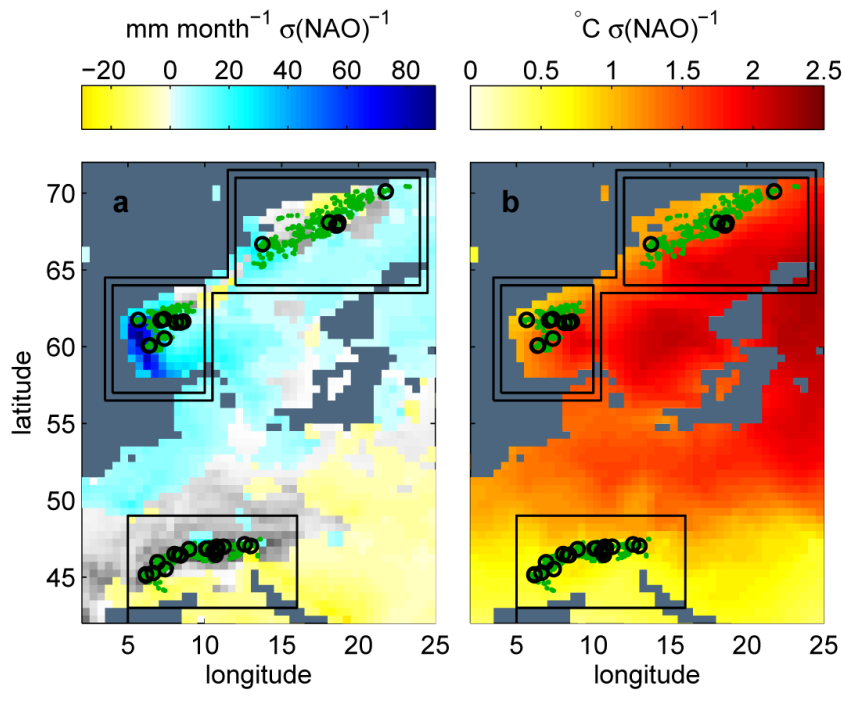

Fig. 1. Maps of regression coefficients of monthly total precipitation (a) and monthly mean temperature (b) on the NAO index (shading), values where the correlation between NAO index and precipitation/temperature is below the $99 \%$ confidence interval have been omitted. Shown are the regression coefficients of the month with the maximum NAO effect, which are generally winter months. Gray background shading: Topography of the CRU TS 3.0 data. Black markers: locations of the glaciers with more than 12 mass balance measurements. Green dots: locations of the glaciers contained in the WGI-XF data base. The boxes indicate the locations of the regions referred to in the text, figures, and tables.

\section{Glacier mass balance models}

\subsection{Individually trained and mean model}

The area-integrated annual mass balance MB of a glacier can be understood as the sum of the monthly precipitation onto the glacier's surface and monthly run off from the glacier. In Marzeion et al. (2012), the modelled mass balance $\mathrm{MB}_{\text {model }}$ is, therefore, derived by introducing two parameters, $a$ and $\mu$, such that

$\mathrm{MB}_{\text {model }}=\sum_{i=1}^{12}\left(a P_{i}-\mu\left(\max \left(0, T_{i}\right)\right)\right)$

where $i$ indicates the month, $P_{i}$ is the monthly solid precipitation onto the glacier surface (in their of case obtained from HISTALP data, which includes specific information on the solid fraction of total precipitation), $T_{i}$ is the monthly mean air temperature at the location of the glacier terminus (in their case obtained from HISTALP data, corrected with a temperature lapse rate for any differences between the height of the glacier terminus ${ }^{4}$ and the height of the HISTALP data point).

\footnotetext{
${ }^{4}$ Terminus elevation and glacier geometry were assumed to be constant throughout the modelled period, i.e., dynamic responses of the glaciers to mass changes were neglected. See
} 
In this model, $a$ can be understood as a parameter representing effects of a precipitation lapse rate, aeolian transport of snow and avalanching, and $\mu$ can be understood as a parameter relating monthly mean temperatures at the glacier terminus to production of glacier melt. For each individual glacier with $N$ existing annual mass balance measurements $\mathrm{MB}_{\text {measured, }}$, the optimal parameters $a_{\mathrm{opt}}$ and $\mu_{\mathrm{opt}}$ can be estimated by requiring that the mean square error

mse $_{\text {model }}=\frac{1}{N} \sum_{k=1}^{N}\left(\mathrm{MB}_{k, \text { measured }}-\mathrm{MB}_{k, \text { model }}\right)^{2}$,

where $k$ is the year, is minimal. From this procedure, individual parameters estimates can be derived for each glacier with existing mass balance measurements (individually trained model). If mass balance measurements exist for a number of glaciers within the region of interest, it is possible to construct the mass balance of an unsampled glacier in that region, by applying the the mean of the parameters from the individually trained models to the unsampled glacier. We refer to this as the mean model.

While for a detailed discussion of the concept of the individually trained and the mean model we refer to Marzeion et al. (2012), the transfer of the model from the HISALP to the CRU TS 3.0 data as the driving dataset necessitates the estimation of the solid fraction of precipitation onto the glacier surface, and a new validation of model performance and robustness. This is achieved by a cross validation procedure presented in Sect. 2.3.

\subsection{Climatologically derived model}

Kaser et al. (2010) develop a model of the monthly climatological glacier mass balance, based on monthly climatological precipitation and temperature at the glacier location, in order to estimate the potential of seasonally delayed runoff to water availability in large river basins. For a glacier in equilibrium with monthly climatological temperatures and precipitation, the annual mass gain from precipitation $\sum_{i=1}^{12} P_{i, \text { clim }}$, where $P_{i, \text { clim }}$ is the climatological monthly solid precipitation integrated over the surface of the glacier, has to equal the annual mass loss by melting of ice, $\sum_{i=1}^{12} R_{i, \text { clim }}$, where $R_{i, \text { clim }}$ is the climatological monthly melt from the glacier. The determination of $R_{i, \text { clim }}$ requires the consideration of energy budget of the glacier (see e.g., Kuhn, 1987; Oerlemans, 2000; Mölg and Hardy, 2004), but air temperature is a reasonable proxy for the energy available to the glacier for producing melt (Sicart et al., 2008; Ohmura, 2001). Therefore, we assume $R_{i, \text { clim }}=-\mu_{\text {clim }}\left(\max \left(0, T_{i, \text { clim }}-T_{\text {melt }}\right)\right)$, where $T_{i, \text { clim }}$ is the monthly climatological air temperature at the glacier terminus and $T_{\text {melt }}$ is the monthly mean air temperature above

Marzeion et al. (2012) for a detailed discussion on the implications of this assumption. which melt at the glacier terminus occurs. $T_{\text {melt }}$ does not necessarily have to be $0^{\circ} \mathrm{C}$, since the diurnal cycle and intramonthly variability may lead to above-freezing temperatures even if the monthly mean is below $0{ }^{\circ} \mathrm{C}$, but it turns out that the model performance is both quite insensitive to the exact value of $T_{\text {melt }}$, and highest for $T_{\text {melt }}=0{ }^{\circ} \mathrm{C}$ (see Marzeion et al. (2012) for a more detailed discussion), so that we assume $T_{\text {melt }}=0{ }^{\circ} \mathrm{C}$ in the following.

Then, if we assume that a glacier in its current extent is in equilibrium with monthly climatological temperatures and precipitation (see Sect. 4 for a discussion of the implications of this assumption), the annual climatological mass balance has to fulfill

$\mathrm{MB}_{\text {clim }}=\sum_{i=1}^{12}\left(P_{i, \operatorname{clim}}+R_{i, \operatorname{clim}}\right)=0$,

which leads directly to an estimate of $\mu_{\text {clim }}$ (see Eq. 6).

The variable annual mass balance of a glacier can then be estimated as

$\mathrm{MB}_{\text {model }}=\sum_{i=1}^{12}\left(P_{i}-\mu_{\mathrm{clim}}\left(\max \left(0, T_{i}\right)\right)\right)$.

where $P_{i}$ is the monthly solid precipitation onto the glacier surface and $T_{i}$ is the monthly mean air temperature at the location of the glacier terminus.

The CRU CL 2.0 dataset (New et al., 2002) ${ }^{5}$ includes $10^{\prime} \times 10^{\prime}$ resolution fields of monthly mean climatological temperature and total precipitation, while the CRU TS 3.0 dataset (Mitchell and Jones, 2005) provides time series of monthly temperature and total precipitation on a $30^{\prime} \times 30^{\prime}$ grid. Therefore, it is possible to estimate vertical gradients of temperature and precipitation on the scale of the CRU TS 3.0 grid based on the CRU CL 2.0 climatology, if the topography around the location of interest is rough, i.e., if there is spread in the elevation of the CRU CL 2.0 grid surrounding the location of interest, and if the horizontal gradients in the area of interest are small compared to the vertical gradients. The first condition is fulfilled for all the locations of interest in this study, since the glaciers are located in mountainous terrain. We assume that the second condition is only fulfilled for temperature, since especially in Scandinavia, the horizontal gradients in precipitation are large (see Sect. 4 for a more detailed discussion). Therefore, we estimate vertical lapse rates of temperature for all glaciers in the WGI-XF dataset by regressing temperature in $3 \times 3$ CRU CL 2.0 grid points around the location of the glacier onto elevation. Figure $2 \mathrm{a}$ shows the result. The correlation between temperature and elevation is very high (typically $>0.95$ ) and above the $95 \%$ confidence interval for all glaciers. For precipitation, we assume a lapse rate of $2 \%$ precipitation increase every $100 \mathrm{~m}$ altitude increase, which use to estimate precipitation at the mean elevation of the glacier, and subsequently apply as the

\footnotetext{
$5_{\text {available at http://www.cru.uea.ac.uk/cru/data/hrg/tmc/ }}$
} 

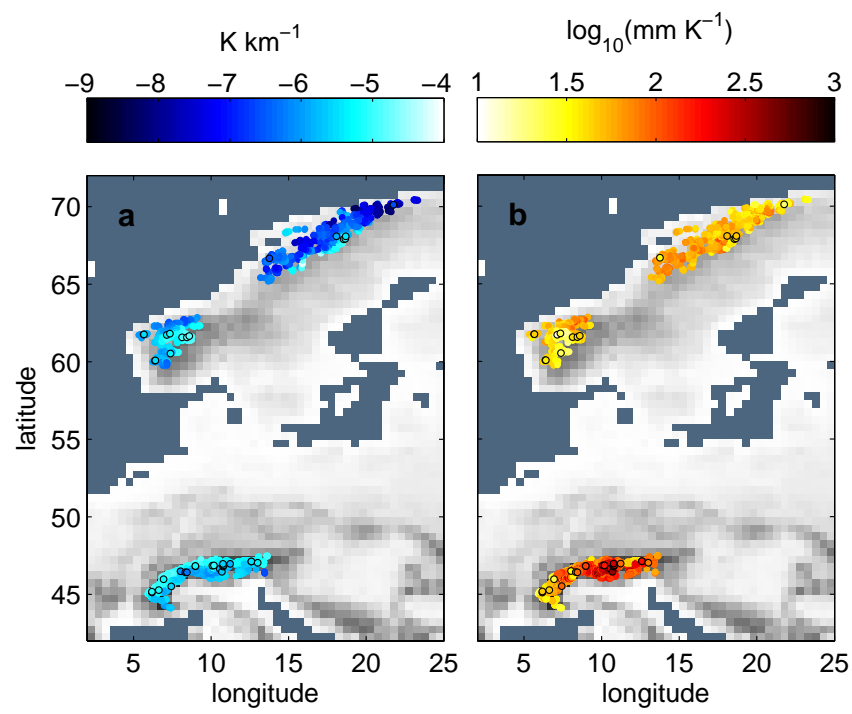

Fig. 2. Maps of the model parameters of the climatologically derived model: (a) temperature lapse rates. Values where the correlation between temperature and elevation is below the $95 \%$ confidence interval have been omitted. (b) $\mu_{\text {clim. }}$. Markers with black circle indicate the results of the glaciers with more than 12 existing measurements of annual mass balance. Gray background shading: topography of the CRU TS 3.0 data.

precipitation estimate representative of the whole glacier surface. This lapse rate is on the lower side of the values typically gained from determining the lapse rates based on the CRU CL 2.0 climatology in those areas where the horizontal gradients in the climatology are small.

In order to estimate $\mu_{\text {clim }}$ for each glacier, we first determine the monthly climatological temperature $T_{i, \text { clim }}$ at the glacier terminus as

$T_{i, \operatorname{clim}}=T_{i, \mathrm{CRU}_{\mathrm{clim}}}+\gamma_{\mathrm{T}}\left(z_{\text {terminus }}-z_{\mathrm{CRU}}\right)$,

where $T_{i, \mathrm{CRU}_{\text {clim }}}$ is the monthly climatological temperature of the CRU TS 3.0 dataset at the location of the glacier ${ }^{6}$, $\gamma_{\mathrm{T}}$ is the temperature lapse rate at the location of the glacier determined as described above, $z_{\text {terminus }}$ is the altitude of the glacier terminus and $z_{\mathrm{CRU}}$ is the altitude of the CRU TS 3.0 grid point.

We then estimate the fraction of solid precipitation by assuming that if the temperature at terminus elevation is below $2{ }^{\circ} \mathrm{C}$, solid precipitation equals total precipitation. If the temperature at the highest elevation of the glacier (obtained using $\gamma_{\mathrm{T}}$ ) is above $2{ }^{\circ} \mathrm{C}$, there is no solid precipitation. Within this range, we interpolate the solid fraction linearly, implying that for precipitation fractionation, we assume a distribution of area that is constant with elevation. Note that while the

\footnotetext{
${ }^{6}$ It would be possible to use the CRU CL 2.0 dataset here. But for reasons of consistency when we apply the climatologically derived model in the variable climate, we use the monthly climatology derived from CRU TS 3.0 here.
}

choice of $2{ }^{\circ} \mathrm{C}$ as the threshold temperature is in principle arbitrary and may seem high, it yields the best model performance in the cross validation. The reason may be processes such as water retention or refreezing in the snow pack that may occur during cold, but liquid, precipitation events.

$$
\frac{\sum_{i=1}^{12} P_{i, \mathrm{clim}}}{\sum_{i=1}^{12} \max \left(0, T_{i, \mathrm{clim}}\right)}=\mu_{\mathrm{clim}},
$$

where $P_{i, \text { clim }}$ is the monthly climatological solid precipitation estimate based on the CRU TS 3.0 dataset at the location of the glacier, gives the estimate of $\mu_{\text {clim }}$. Figure $2 \mathrm{~b}$ shows $\mu_{\text {clim }}$ for each of the glaciers considered in this study.

\subsection{Model validation}

The individually trained, and the mean model, depend on the measured mass balance values of the glaciers. In order to validate these models using the measured mass balances, we perform a cross validation of these two models (Michaelsen, 1987, and Hofer et al., 2010, give a detailed description of cross validation applications in climate). The climatologically derived model is built independent of the measured mass balances and can, therefore, directly be validated with the measurements.

\subsubsection{Cross validation of the individually trained model}

As in Marzeion et al. (2012), for each glacier in the region of interest with existing mass balance measurements, we first construct a time series of modelled annual mass balance $\mathrm{MB}_{\text {model }}$, where each annual value is independent of the measured value of that year. This is achieved by performing the model optimization required for estimating the model parameters $a_{\mathrm{opt}}$ and $\mu_{\mathrm{opt}} N$ times, where $N$ is the number of mass balance measurements, leaving out of the optimization the years $k \pm t_{\text {lag }}$, where $k$ is the year of the measurement, and $t_{\text {lag }}$ is the length of autocorrelation in the measured mass balance time series (typically, one year). This yields the model parameters $a_{k \text {,cross }}$ and $\mu_{k \text {,cross }}$, which are then used to de-

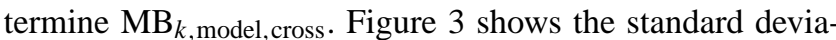
tion of $a_{k \text {,cross }}$ and $\mu_{k, \text { cross }}$ for all glacier with existing mass balance measurements, as a function of the number of mass balance measurements existing for that glacier. It becomes apparent that the robustness of the estimates of the model parameters increases with the number of mass balance measurements and that a minimum number of measurements is necessary to achieve reliable estimates of $a_{k \text {,cross }}$ and $\mu_{k \text {,cross }}$. For this reason, we reject all glaciers with fewer than $12 \mathrm{yr}$ of mass balance measurements from all further analysis (note that the minimum number of mass balance measurements is a subjective choice, but the results presented here do not depend strongly on the exact number).

Figure 4d shows the modelled versus measured mass balances (normalized) of the individually trained model for all glaciers with more than 12 measured mass balances, panel 


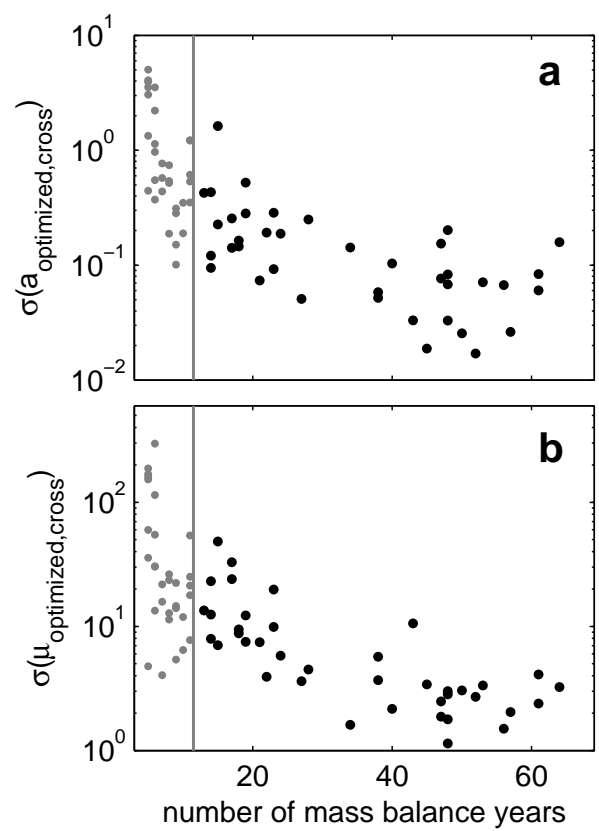

Fig. 3. Standard deviation of $a_{k \text {,cross }}$ (a) and $\mu_{k \text {,cross }}$ (b) as a function of the number of mass balance measurements. Black dots are the values of glaciers accepted into the final set, gray dots are those of the glaciers rejected from the final set. The gray vertical line indicates the minimum number of mass balance measurements (12 yr) necessary to obtain robust results for $a_{\text {optimized }}$ and $\mu_{\text {optimized }}$.
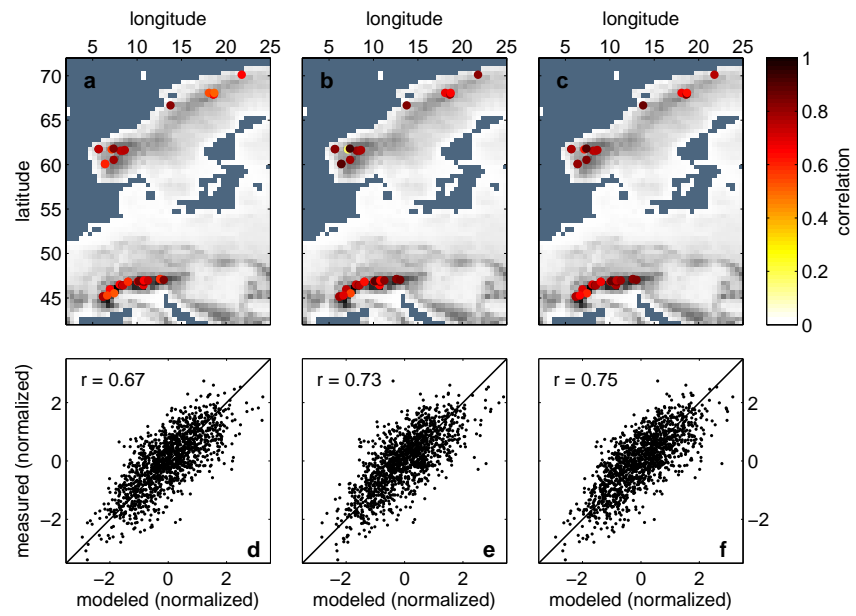

Fig. 4. Upper row: correlation coefficients of the individually trained (a), mean (b), and climatologically derived model (c) for all glaciers with more than 12 measured annual mass balances. See Tables 1 (for $\mathbf{a}$ and $\mathbf{b}$ ) and 2 (for $\mathbf{c}$ ) for the mean values and standard deviation. Gray background shading: topography of the CRU TS 3.0 data. Lower row: modelled versus measured normalized annual mass balances of the individually trained model (d) and the mean model (e) obtained by cross validation, and of the climatologically derived model (f), for all glaciers with more than 12 measured mass balances.

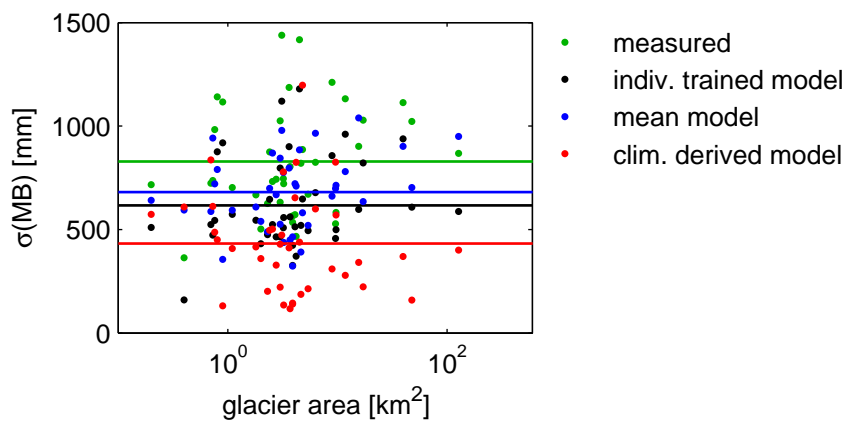

Fig. 5. Standard deviation of the annual mass balance plotted against the area of the glaciers. Green dots show $\mathrm{MB}_{\text {measured }}$, black dots show the values of the individually trained model, blue dots show the results of the mean model and red dots show the results of the climatologically derived model. Horizontal lines show the respective means.

a shows the correlation coefficient for each glacier. We also calculate the bias of the model, and the skill score

$\mathrm{SS}=1-\frac{\text { mse }_{\text {model }}}{\text { mse }_{\text {ref }}}$,

where mse $_{\text {model }}$ is the mean-square-error of $\mathrm{MB}_{\text {model }}$, and mse $_{\text {ref }}$ is the mean-square-error of a reference model (in this case, we use the mean of the measured mass balances as the reference model). Figure 5 shows that the variability of the modelled time series is smaller than that of the measured mass balance time series. But still, there is considerable skill in the modelled time series (mean skill score 0.51), and the correlation between modelled and measured mass balances is reasonably high (mean value of 0.67 ). The results of the cross validation of the individually trained model are summarized in Table 1 (see Marzeion et al. (2012) for a more detailed description and discussion of the cross validation procedure).

We finally determine $a_{\text {opt }}$ and $\mu_{\text {opt }}$ as the mean values of $a_{k \text {,cross }}$ and $\mu_{k \text {,cross }}$, and apply them in Eq. (1) to obtain the time series $\mathrm{MB}_{\text {model }}$ of the individually trained model over the entire period of data available in the CRU TS 3.0 dataset. Figure 6a shows the result for an example glacier, Ålfotbreen ${ }^{7}$ in western Norway (black line), together with the measured mass balances (green line).

\subsubsection{Cross validation of the mean model}

In order to cross validate the mean model, we construct time series of $\mathrm{MB}_{\text {model }}$ for each glacier with more than 12 existing mass balance measurements, independent of the mass balance measurements of that glacier. This is achieved by determining $a_{\text {mean,cross }}$ and $\mu_{\text {mean,cross }}$ as the mean of $a_{\text {opt }}$ and $\mu_{\mathrm{opt}}$ of all the glaciers in the region, except for the glacier where the cross validation is being carried out.

\footnotetext{
${ }^{7}$ Ålfotbreen was chosen as an example, because with respect to glaciers in western Norway, it exhibits a typical relation to the NAO, and it has a long history of mass balance measurements.
} 
Table 1. Summary of parameters and cross validation results of the individually trained (first two lines) and the mean model (remaining lines). Number of glaciers with mass balance measurements, and total number of mass balance measurements are also given. All parameter values $\left(a_{\mathrm{opt}}\right.$ and $\left.\mu_{\mathrm{opt}}\right)$, correlations $(r)$, skill scores (SS), and biases given are the mean values obtained during the cross validation procedure, with their standard deviation. Negative skill scores imply zero skill and have, therefore, been replaced with zero for the calculation of the mean and standard deviation of the skill scores.

\begin{tabular}{|c|c|c|c|c|c|c|c|}
\hline & $\begin{array}{c}\text { No. } \\
\text { Glaciers }\end{array}$ & $\begin{array}{l}\text { No. } \\
\text { MB }\end{array}$ & $a_{\mathrm{opt}}$ & $\mu_{\mathrm{opt}}\left[\mathrm{mm} \mathrm{K}^{-1}\right]$ & $r$ & SS & Bias [mm] \\
\hline individually trained & 71 & 1579 & $2.10 \pm 1.39$ & $71 \pm 150$ & $0.50 \pm 0.45$ & $0.46 \pm 0.24$ & $-124 \pm 1484$ \\
\hline $\begin{array}{l}\text { individually trained } \\
\text { (no. } \mathrm{MB}>12 \text { ) }\end{array}$ & 39 & 1339 & $2.10 \pm 1.54$ & $107 \pm 51$ & $0.67 \pm 0.15$ & $0.51 \pm 0.14$ & $0 \pm 19$ \\
\hline $\begin{array}{l}\text { Northern Scandinavia } \\
(\text { no. } \mathrm{MB}>12)\end{array}$ & 7 & 208 & $4.10 \pm 1.77$ & $116 \pm 60$ & $0.73 \pm 0.10$ & $0.09 \pm 0.15$ & $-543 \pm 1714$ \\
\hline $\begin{array}{l}\text { Southern Scandinavia } \\
(\text { no. } \mathrm{MB}>12 \text { ) }\end{array}$ & 10 & 372 & $2.95 \pm 0.78$ & $76 \pm 26$ & $0.72 \pm 0.15$ & $0.12 \pm 0.25$ & $-544 \pm 2627$ \\
\hline $\begin{array}{l}\text { Scandinavia } \\
(\text { no. } \mathrm{MB}>12)\end{array}$ & 17 & 580 & $3.42 \pm 1.36$ & $93 \pm 46$ & $0.73 \pm 0.13$ & $0.14 \pm 0.24$ & $-587 \pm 2375$ \\
\hline $\begin{array}{l}\text { Alps } \\
(\text { no. } M B>12)\end{array}$ & 22 & 759 & $1.08 \pm 0.59$ & $118 \pm 52$ & $0.74 \pm 0.11$ & $0.22 \pm 0.31$ & $-506 \pm 2393$ \\
\hline $\begin{array}{l}\text { all } \\
(\text { no. } M B>12)\end{array}$ & 39 & 1339 & $2.10 \pm 1.54$ & $107 \pm 51$ & $0.73 \pm 0.14$ & $0.07 \pm 0.16$ & $-258 \pm 3039$ \\
\hline
\end{tabular}

Marzeion et al. (2012) show that if the Alps are considered as one region, the mean model yields reasonable results. Here, we define 5 different regions for determining the mean parameters: northern Scandinavia, southern Scandinavia, Scandinavia (i.e., northern and southern Scandinavia combined), the Alps and Europe as one region containing all glaciers considered here. The outlines of the different regions are shown in Fig. 1. The results of the cross validation of the mean model are summarized in Table 1 . If measured by correlation between modelled and measured mass balances, the performance of the mean model is higher than that of the individually trained model, independent of how the region is defined. The mean model works best for the Alps (mean correlation of 0.74 ), but the performance suffers only little when applied over all of Europe (mean correlation 0.73). The fact that the correlation improves for the mean model compared to the individually trained model can be understood as the result of a vastly increased data basis of the mean model compared to the individually trained model, i.e., many more measured mass balances values entering the determination of the model parameters. The mean model also slightly improves the representation of variability of the mass balances (Fig. 5), but it exhibits a considerable bias (see Table 1). As a result, the skill score becomes negligible (except for the Alps). This implies that the model's results cannot be used in applications where absolute values of the mass balance are needed. But for correlation-based analyses, which do not depend on bias and the amplitude of the variability, the model results are applicable.

Figure 4e shows the modelled versus measured mass balances (normalized) of the mean model for all glacier with more than 12 measured mass balances (the mean being applied over all of Europe), panel b shows the correlation coefficient for each glacier.

We finally determine $a_{\text {mean }}$ and $\mu_{\text {mean }}$ as the mean values of $a_{\mathrm{opt}}$ and $\mu_{\mathrm{opt}}$, and apply them in Eq. (1) to obtain the time series $\mathrm{MB}_{\text {model }}$ of the mean model over the entire period of data available in the CRU TS 3.0 dataset. Figure $6 \mathrm{~b}$ shows the result for Ålfotbreen (black line), together with the measured mass balances (green line).

\subsubsection{Validation of the climatologically derived model}

Since the climatologically derived model is built independent of mass balance measurements, it can be validated directly using the measured mass balances of glaciers where available. This would be possible independent of the number of mass balance measurements, but in order to be able to directly compare the climatologically derived model with the individually trained and the mean model, we show here the validation based only on those glaciers for which more than 12 measured mass balances are available. Figure 4f, shows the modelled versus measured mass balances (normalized) of the climatologically derived model, panel c shows the correlation coefficient for each glacier. From Fig. 5 it is apparent that a weakness of the climatologically derived model is an underestimation of the variability of the mass balances. But the summary of the validation (see Table 2) shows that the climatologically derived model shows an improvement over the individually trained and mean models in terms of correlation, and over the mean model in terms of skill score. 


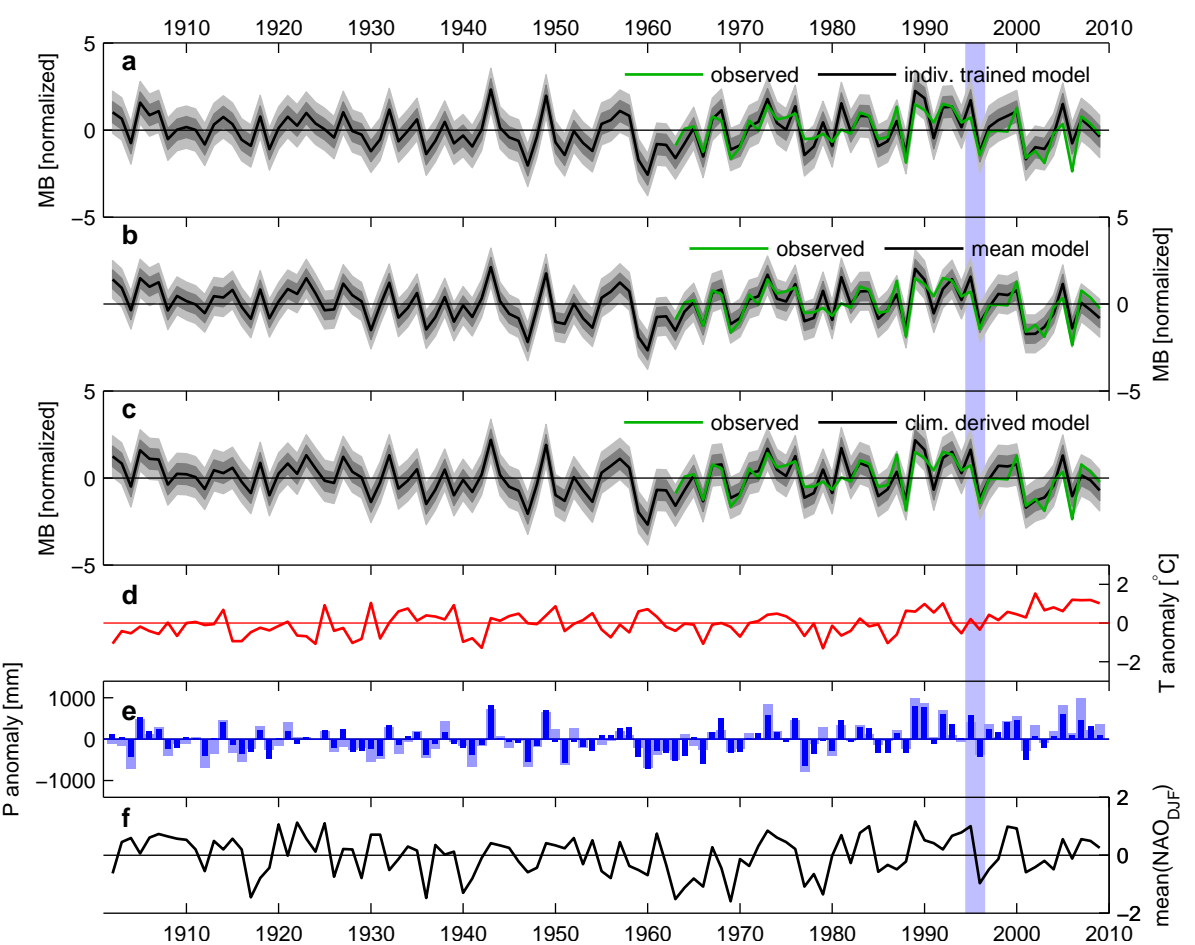

Fig. 6. Timeseries of the reconstruction for Ålfotbreen. (a) green: standardized $\mathrm{MB}_{\text {measured }}$, black: standardized $\mathrm{MB}_{\text {model }}$, light gray shading: $\pm 2 \cdot$ rmse, dark gray shading: $\pm 1 \cdot$ rmse. (b) green: standardized $\mathrm{MB}_{\text {measured }}$, black: standardized $\mathrm{MB}_{\text {mean model }}$, light gray shading: \pm 2 . rmse, dark gray shading: $\pm 1 \cdot$ rmse. (c) green: standardized $\mathrm{MB}_{\text {measured }}$, black: standardized $\mathrm{MB}_{\text {clim model }}$, light gray shading: $\pm 2 \cdot$ rmse, dark gray shading: $\pm 1 \cdot$ rmse. (d) annual temperature anomaly at the location of the glacier. (e) annual precipitation anomaly at the location of the glacier, light blue: total precipitation, dark blue: estimated solid precipitation. (f) winter mean of the NAO index. The vertical light blue bar indicates the two years shown in detail in Fig. 7. Equivalent figures are available for all 39 glaciers with more than 12 measured mass balance values as Supplement.

Table 2. Summary of the model parameters and validation results of the climatologically derived model. All numbers given are the mean values with their standard deviation.

\begin{tabular}{lcccr}
\hline & $\mu_{\text {clim }}\left[\mathrm{mm} \mathrm{K}^{-1}\right]$ & $r$ & SS & Bias $[\mathrm{mm}]$ \\
\hline N. Scandinavia & $35 \pm 11$ & $0.75 \pm 0.09$ & $0.11 \pm 0.10$ & $35 \pm 579$ \\
S. Scandinavia & $35 \pm 12$ & $0.77 \pm 0.07$ & $0.24 \pm 0.17$ & $-237 \pm 413$ \\
Scandinavia & $35 \pm 11$ & $0.76 \pm 0.08$ & $0.19 \pm 0.16$ & $-125 \pm 491$ \\
Alps & $128 \pm 88$ & $0.74 \pm 0.11$ & $0.31 \pm 0.18$ & $62 \pm 284$ \\
all & $87 \pm 81$ & $0.75 \pm 0.10$ & $0.26 \pm 0.18$ & $-19 \pm 394$ \\
\hline
\end{tabular}

Figure $6 \mathrm{c}$ shows the result of the climatologically derived model for Ålfotbreen (black line), together with the measured mass balances (green line).

\section{Results}

The (cross) validation of the three different models has shown that for a correlation-based analysis, the climatologically derived model provides the most reliable results. Therefore, in the following, we discard the individually trained and mean models, and only apply the climatologically derived model to construct mass balance time series for all 7735 in- dividual glaciers contained in the WGI-XF dataset within the domain of interest, covering the entire time period of CRU data availability.

\subsection{Decomposition of the forcing fields}

In order to bring out the influence of the NAO on the glacier mass balances in Europe, we first determine $T_{\text {glacier }}$ as the temperature at the glacier terminus using Eq. (5) and $P_{\text {glacier }}$ as the estimated solid precipitation onto the glacier surface from CRU TS 3.0, and then decompose $T_{\text {glacier }}$ and $P_{\text {glacier }}$ 
$T_{\text {glacier }}=T_{\text {glacier }_{\text {clim }}}+T_{\text {glacier }_{\mathrm{NAO}}}+T_{\text {glacier }}^{\prime}$,

$P_{\text {glacier }}=P_{\text {glacier }_{\text {clim }}}+P_{\text {glacier }_{\mathrm{NAO}}}+P_{\text {glacier }}^{\prime}$,

where the subscript clim denotes the monthly mean climatological values, the subscript NAO denotes monthly anomalies associated with NAO variability and the prime denotes all other anomalies. In order to determine $T_{\text {glacier }}{ }_{\mathrm{NAO}}$ and $P_{\text {glacier }}$ NAO , we perform a regression of $T_{\mathrm{CRU}}$ and $P_{\mathrm{CRU}}$ on the monthly NAO index (Hurrell, 1995b) ${ }^{8}$, individually for each month of the year. Generally speaking, the NAO influence is strongest in winter, with positive NAO anomalies leading to above-average temperatures all over Europe, while the precipitation anomalies tend to be positive in northern Europe (with exceptions in the northwestern part of northern Norway), and negative around the Mediterranean (Fig. 1, see Hurrell et al., 2003, for a detailed discussion of the impacts of the NAO on European climate).

Figure 7 shows example results of the decomposition for the location of Ålfotbreen, for the hydrological years 1995 and 1996 (vertical, light blue bar in Fig. 6). The comparison of panel a with panels $d$ and $g$ shows that while the NAO variability does not show a strong seasonality, its impacts on temperature and precipitation are only evident during winter.

\subsection{Constructing the mass balance time series}

For each glacier we then construct a total of 5 time series of mass balance variability:

1. $\mathrm{MB}_{\text {clim }}=P_{\text {glacier }_{\text {clim }}}-\mu_{\text {clim }}\left(\max \left(0, T_{\text {glacier }_{\text {clim }}}\right)\right)$

is the monthly, climatological mass balance of the glacier, where $\sum_{i=1}^{12} \mathrm{MB}_{i, \mathrm{clim}}=0, i$ indicating the months of the hydrological year, follows directly from Eq. (7). $\mathrm{MB}_{\text {clim }}$ is shown in Fig. $7 \mathrm{~h}$.

2. $\mathrm{MB}_{\text {anom }}=\left[P_{\text {glacier }}-\mu_{\text {clim }}\left(\max \left(0, T_{\text {glacier }}\right)\right)\right]-\mathrm{MB}_{\text {clim }}$

is the monthly deviation of the mass balance from the climatological mass balance, shown in Fig. 7 i.

3. $\mathrm{MB}_{\mathrm{NAO}}=\left[\left(P_{\text {glacier }_{\mathrm{NAO}}}+P_{\text {glacier }_{\text {clim }}}\right)\right.$

$$
\left.-\left(\mu_{\text {clim }}\left(\max \left(0, T_{\text {glacier }_{\mathrm{NAO}}}+T_{\text {glacier }_{\text {clim }}}\right)\right)\right)\right]-\mathrm{MB}_{\text {clim }}
$$

is the monthly deviation of the mass balance from the climatological mass balance associated with NAO variability, shown in Fig. 7j.

4. $\mathrm{MB}\left(T_{\mathrm{NAO}}, P_{\text {clim }}\right)=\left[P_{\text {glacier }_{\text {clim }}}-\left(\mu_{\text {clim }}\left(\max \left(0, T_{\text {glacier }_{\mathrm{NAO}}}\right.\right.\right.\right.$ $\left.\left.\left.\left.+T_{\text {glacier }_{\text {clim }}}\right)\right)\right)\right]-\mathrm{MB}_{\text {clim }}$

is the monthly deviation of the mass balance from the climatological mass balance associated with only NAO temperature variability, shown in Fig. 7k.

\footnotetext{
8 available at http://www.cgd.ucar.edu/cas/jhurrell/indices.html
}

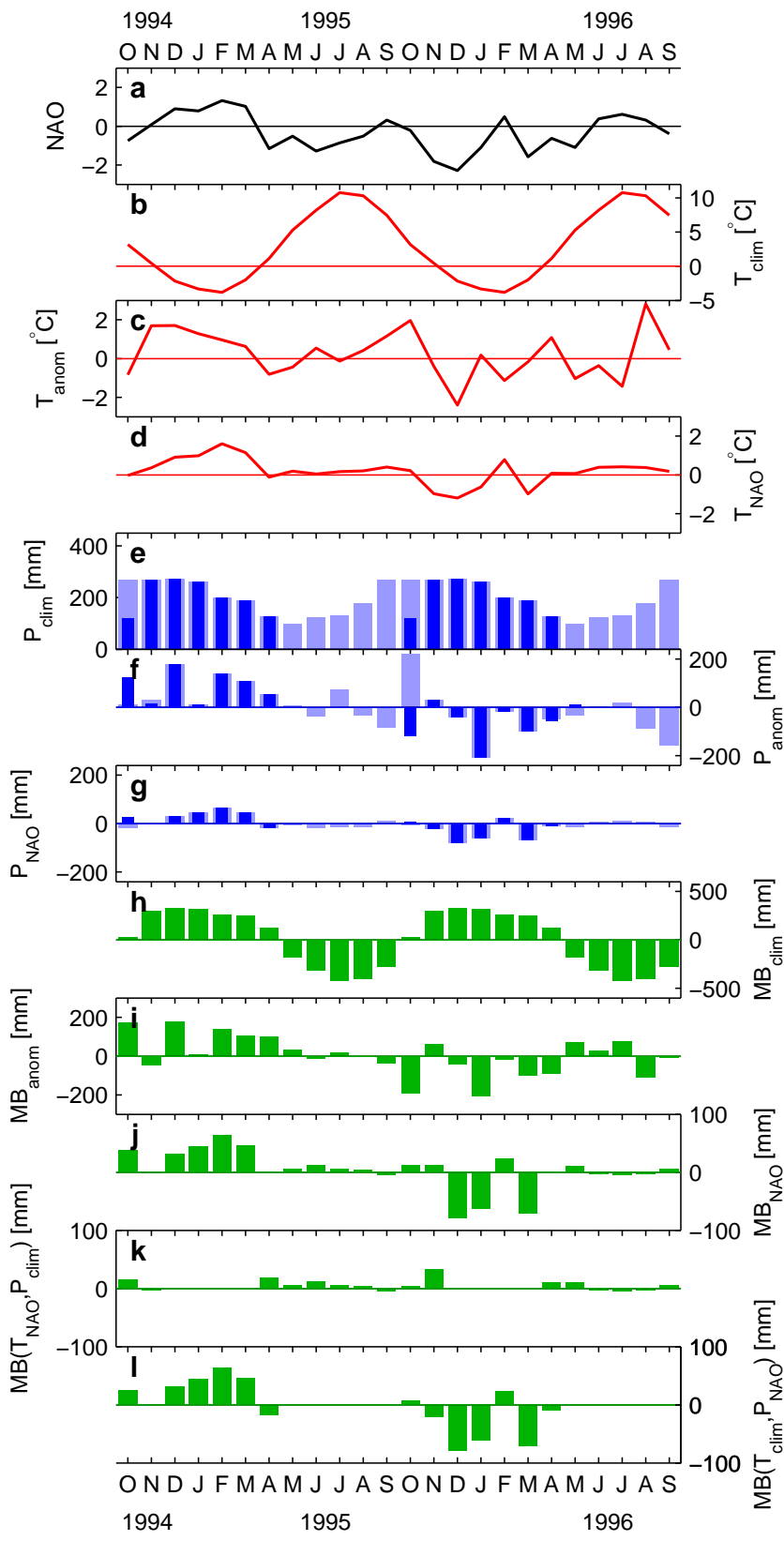

Fig. 7. Detailed example of the monthly time series of the reconstruction for Ålfotbreen for the hydrological years 1995 and 1996. (a) NAO index. (b) Temperature climatology, $T_{\text {glacier }_{\text {clim }}}$. (c) Temperature anomaly, $T_{\text {glacier }_{\mathrm{NAO}}}+T_{\text {glacier }}^{\prime}$. (d) Temperature anomaly associated with NAO, $T_{\text {glacier }_{\mathrm{NAO}}}$. (e) Precipitation climatology, $P_{\text {glacier }_{\text {clim }}}$ (f) Precipitation anomaly, $P_{\text {glacier }_{\mathrm{NAO}}}+P_{\text {glacier }}^{\prime}$ (g) Precipitation anomaly associated with NAO, $P_{\text {glacier }_{\mathrm{NAO}}}$. (In panels e-g: light blue: total precipitation, dark blue: estimated solid precipitation) (h) Mass balance climatology, $\mathrm{MB}_{\mathrm{clim}}$. (i) Mass balance anomaly, $\mathrm{MB}_{\text {anom. (j) Mass balance anomaly associated }}$ with NAO variability in temperature and precipitation, $\mathrm{MB}_{\mathrm{NAO}}$. (k) Mass balance anomaly associated with NAO temperature anomaly, $\mathrm{MB}\left(T_{\mathrm{NAO}}, P_{\mathrm{clim}}\right)$. (l) Mass balance anomaly associated with NAO precipitation anomaly, $\mathrm{MB}\left(T_{\mathrm{clim}}, P_{\mathrm{NAO}}\right)$. Equivalent figures are available for all 39 glaciers with more than 12 measured mass balance values as Supplement. 


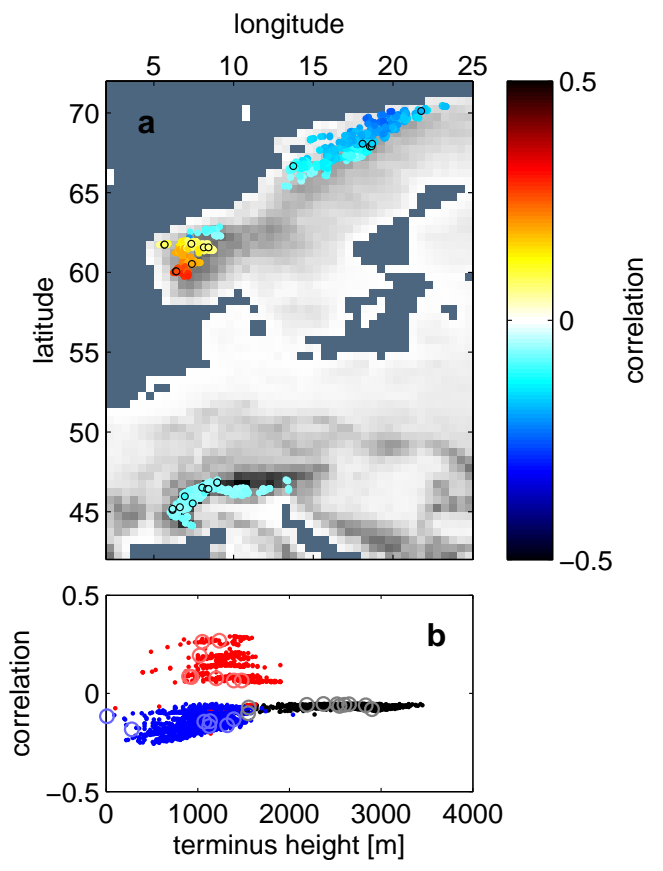

Fig. 8. Correlation between modelled monthly mass balance anomalies, i.e., $\mathrm{MB}_{\text {anom }}$, and monthly NAO index. Markers with black circle (a) and circle markers (b) indicate the results of the glaciers with more than 12 existing measurements of annual mass balance. Values below the $95 \%$ confidence interval have been omitted. Gray background shading: topography of the CRU TS 3.0 data. In panel (b) black is for glaciers in the Alps, red for glaciers in southern Scandinavia, blue for glaciers in northern Scandinavia.

$$
\begin{aligned}
& \text { 5. } \operatorname{MB}\left(T_{\text {clim }}, P_{\mathrm{NAO}}\right)=\left[\left(P_{\text {glacier }_{\mathrm{NAO}}}+P_{\text {glacier }_{\text {clim }}}\right)\right. \\
& \left.-\left(\mu_{\text {clim }}\left(\max \left(0, T_{\text {glacier }_{\text {clim }}}\right)\right)\right)\right]-\mathrm{MB}_{\text {clim }}
\end{aligned}
$$

is the monthly deviation of the mass balance from the climatological mass balance associated with only NAO precipitation variability, shown in Fig. 71.

\subsection{The spatial patterns of NAO influence on mass balance variability}

Figure 8 shows the correlation between monthly NAO index and monthly modelled mass balance anomalies $\mathrm{MB}_{\text {anom }}{ }^{9}$. The strongest relationship between NAO and mass balance becomes apparent in western Norway (confirming the results of Nesje et al. (2000) and Reichert et al. (2001), who investigated single glaciers in these regions). In northern Scandinavia, and in the Alps, the mass balances are anti-correlated with the NAO and in the Alps the connection is generally weaker. In the case of the Alps the anti-correlation is significant only in the western part (here, Reichert et al. (2001)

\footnotetext{
${ }^{9}$ Note in this and the subsequent figures that the glaciers with existing mass balances, where the model validation takes place, are well distributed in the whole sample of WGI-XF glaciers.
}

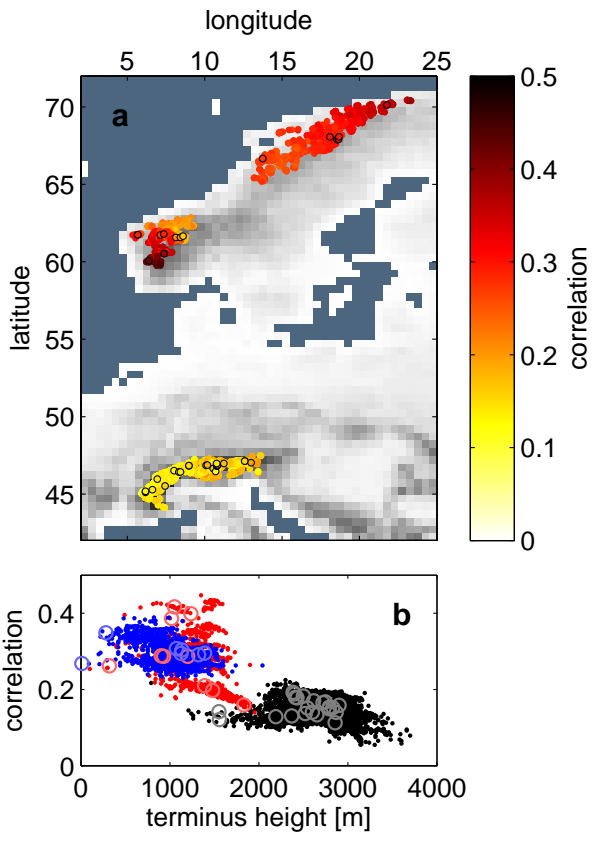

Fig. 9. Correlation between modelled monthly mass balance anomalies obtained using the full variability in the forcing, and modelled monthly mass balance anomalies obtained using only NAO-related variability in the forcing, i.e., between $\mathrm{MB}_{\mathrm{anom}}$ and $\mathrm{MB}_{\mathrm{NAO}}$. Markers with black circle (a) and circle markers (b) indicate the results of the glaciers with more than 12 existing measurements of annual mass balance. Values below the $95 \%$ confidence interval have been omitted. Gray background shading: topography of the CRU TS 3.0 data. In panel (b) black is for glaciers in the Alps, red for glaciers in southern Scandinavia, blue for glaciers in northern Scandinavia.

also find an anti-correlation for Rhonegletscher, but they find the NAO influence to be stronger), and south of the main ridge. Panel $b$ reveals that there is hardly any relation between the correlation and the altitude of the glacier terminus within each region.

As a measure of how strong the NAO influence is on the mass balance, we show correlations between $\mathrm{MB}_{\text {anom }}$ and $\mathrm{MB}_{\mathrm{NAO}}$ in Fig. 9. As is to be expected from Fig. 8, there is a minimum of NAO-driven mass balance variability in midScandinavia, the influence of the NAO is strongest in western Norway and for the glaciers in the very north of Scandinavia. Within the Alps, the NAO influence is generally smaller, but interestingly, slightly grows towards the east.

Since there is a distinct seasonality in the connection between NAO and temperature and precipitation anomalies, it is instructive to look into the seasonality of the mass balances' response to NAO forcing. Figure $10 \mathrm{a}$ and $\mathrm{b}$ show the correlation between monthly NAO index and monthly modelled mass balance anomalies $\mathrm{MB}_{\text {anom }}$ (i.e., the same as Fig. 8), but only during the winter months December, January and February (core winter), when the influence of the NAO 

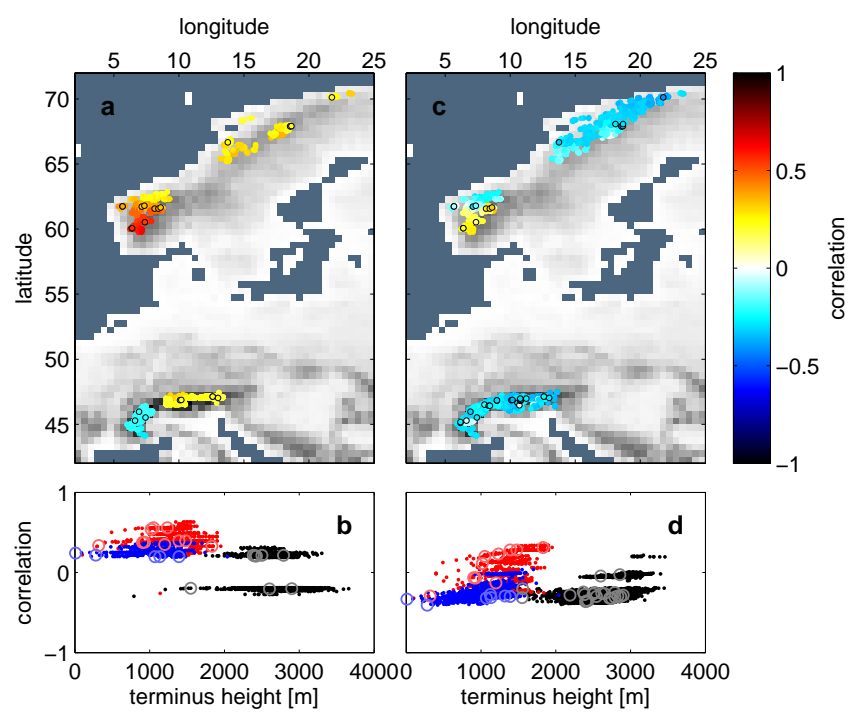

Fig. 10. Mean of the monthly correlations between modelled mass balance anomalies, i.e., $\mathrm{MB}_{\text {anom }}$ and NAO index during December, January and February (a, b), and during March to November (c, d). Markers with black circle $(\mathbf{a}, \mathbf{c})$ and circle markers $(\mathbf{b}, \mathbf{d})$ indicate the results of the glaciers with more than 12 existing measurements of annual mass balance. Values below the $95 \%$ confidence interval have been omitted from the calculation of the mean. Gray background shading: Topography of the CRU TS 3.0 data. In panels (b) and (d) black is for glaciers in the Alps, red for glaciers in southern Scandinavia, blue for glaciers in northern Scandinavia. Note that the correlation values close to zero are the result of calculating the mean of significant, non-zero correlations.

on precipitation and temperature in Europe is strongest. Panels $\mathrm{c}$ and d show the same, but for the remainder of the year.

Generally speaking, the connection between the core winter mass balance and winter NAO is - perhaps not surprisingly - stronger than the connection over the entire year. But the distinction between winter and rest of the year also allows for an insight into the mechanism of NAO influence. During the core winter, even a strong positive NAO, with corresponding warm temperature anomalies does not raise air temperatures at the glaciers' termini above freezing. The core winter signal is, therefore, predominantly a precipitation signal and it becomes apparent that the anti-correlation between NAO and mass balance in northern Scandinavia is caused predominantly outside the core winter season. In western Norway, the relation is more ambiguous: during the entire year, the NAO-mass balance relation contributes to the positive correlation, only in the northern part of southern Norway the temperatures' influence is outside of the core winter is apparent.

In the Alps, a clear distinction is possible between the western and eastern part: in the west, negative core winter accumulation and warmer temperatures outside of the core winter contribute to the anti-correlation with the NAO alike. In the eastern part, however, during the core winter a positive

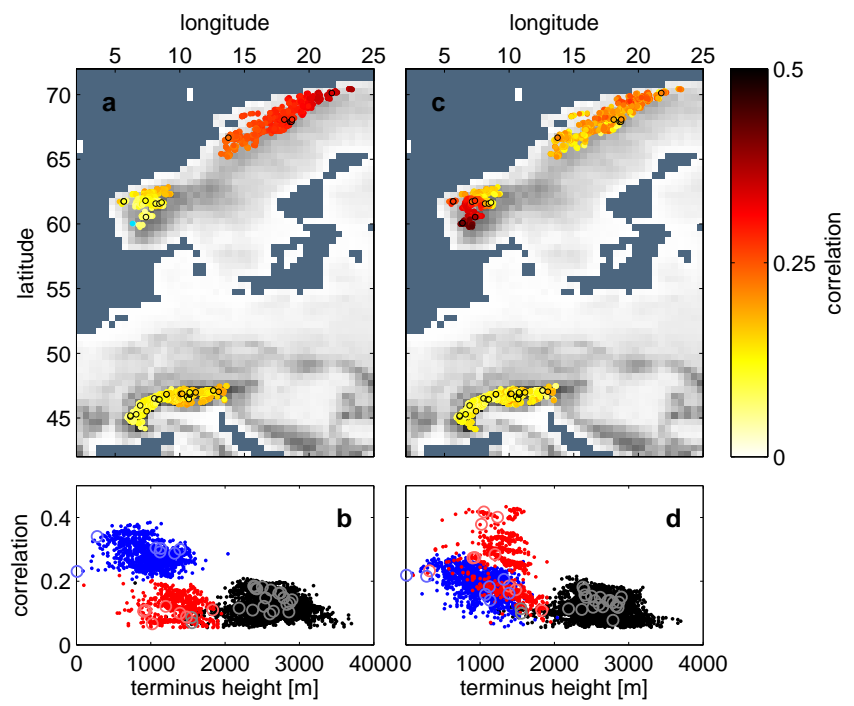

Fig. 11. Correlation between modelled monthly mass balance anomalies obtained using the full variability in the forcing and modelled monthly mass balance anomalies obtained using only NAOrelated temperature variability and climatological precipitation, i.e., between $\mathrm{MB}_{\text {anom }}$ and $\mathrm{MB}\left(T_{\mathrm{NAO}}, P_{\mathrm{clim}}\right)(\mathbf{a}, \mathbf{b})$; and correlation between modelled monthly mass balance anomalies obtained using the full variability in the forcing, and modelled monthly mass balance anomalies obtained using only NAO-related precipitation variability and climatological temperature, i.e., between $\mathrm{MB}_{\text {anom }}$ and $\mathrm{MB}\left(T_{\mathrm{clim}}, P_{\mathrm{NAO}}\right)(\mathbf{c}, \mathbf{d})$. Markers with black circle $(\mathbf{a}, \mathbf{c})$ and circle markers $(\mathbf{b}, \mathbf{d})$ indicate the results of the glaciers with more than 12 existing measurements of annual mass balance. Values below the $95 \%$ confidence interval have been omitted. Gray background shading: topography of the CRU TS 3.0 data. In panels (b) and (d), black is for glaciers in the Alps, red for glaciers in southern Scandinavia, blue for glaciers in northern Scandinavia.

anomaly becomes apparent. This is the region that does not show a significant correlation with the NAO when the entire year is considered. The reason is apparent in panel c: the positive signal caused by core winter accumulation is cancelled by a negative signal during the remainder of the year when warmer temperatures prevail. Since the positive precipitation signal of the NAO is limited to the northern boundary of the Alps (see also Fig. 1), the negative signal shows through in the southern Alps when the whole year is considered.

Another approach to understanding how the relative influences of temperature and precipitation set up the entire signal is followed in Fig. 11, showing the correlation between $\mathrm{MB}_{\text {anom }}$ and $\mathrm{MB}\left(T_{\mathrm{NAO}}, P_{\text {clim }}\right)$ (panels a and $\mathrm{b}$ ), and between $\mathrm{MB}_{\text {anom }}$ and $\mathrm{MB}\left(T_{\text {clim }}, P_{\mathrm{NAO}}\right)$ (panels $\mathrm{c}$ and d). The mass balance anomalies created by NAO-related temperature anomalies correlate with the full mass balance anomalies everywhere, but the correlations are insignificant (and even negative for a few glaciers) in western Norway, i.e., a warm NAO signal contributes negative mass balance anomalies everywhere, but in western Norway, the positive winter mass balance anomalies take the lead. 


\section{Discussion}

One obvious difference between the climatologically derived and the individually trained (and mean) models is that we do not estimate the increase of precipitation with altitude (or potential general underestimation of precipitation, aeolian transport and avalanching, i.e., the parameter $a$ in the individually trained and mean models) in the climatologically derived model individually. One strong benefit of the climatologically derived model is the independence on any mass balance measurements, and the resulting applicability in regions that have fewer mass balance measurements than are necessary to obtain robust parameter estimates for the individually trained (and mean) models. A feasible way of obtaining an estimate of precipitation increase with altitude would be the determination of a vertical precipitation gradient from the CRU CL 2.0 dataset, analogous to the determination of the temperature lapse rates. However, as mentioned above, this approach requires that the vertical gradients in the dataset are large compared to the horizontal gradients. For precipitation, this is not always the case: especially in Scandinavia, the maximum of precipitation is rather close to the coast and not over the highest elevation. Calculating precipitation lapse rates analogous to the temperature lapse rates, therefore, results in negative vertical gradients (i.e., less precipitation with increasing altitude) over large parts of Scandinavia, which is not realistic. For temperature, the problem of mixing horizontal with vertical gradients is less significant, as there is a strong dependence of temperature on altitude by default and the horizontal temperature gradients are small compared to this default vertical gradient. We tested the validity of this approach: prescribing a constant vertical lapse rate in temperature decreases the model's performance (independent of the value of the prescribed lapse rate). If we apply a variable (derived analogous to temperature) precipitation lapse rate, the performance slightly suffers in large parts of Scandinavia and is hardly affected at all in the Alps. We also tested the sensitivity of model performance to changes in the prescribed precipitation lapse rate (i.e., lower or higher than $2 \%$ for every $100 \mathrm{~m}$ elevation increase), and found that while model performance decreases slightly for both lower and higher lapse rates, the results of our study are insensitive to the choice of precipitation lapse rate.

All three models considered here suffer from an underestimation of mass balance variance (see Fig. 5). While this is a typical deficit of simple linear models, it is also likely connected to an underestimation of precipitation amounts in mountainous regions in the CRU data. Ideally, this problem would be overcome by downscaling precipitation (see Jarosch et al., 2012, for glaciological applications of precipitation downscaling), but doing so is out of the scope for this study - especially since underestimated mass balance variance does not affect the results presented here, which are based solely on correlation analysis.
The main deficit of the climatologically derived model compared to the individually trained model is the relatively strong bias (the same is true for the mean model), leading to the weak skill scores. While the bias also does not affect our correlation-based analysis, it does prevent the model from being applied to reconstruct absolute values of mass balance. The construction of the climatologically derived model implies that over the entire CRU TS 3.0 period, the mean mass balance is very close to zero (it is not exactly zero, since the interannual variability in temperature and precipitation is not evenly distributed over the months of the year). The bias is, therefore, a measure of how far away the glaciers are from equilibrium with the climatological forcing.

It is questionable whether the slight advantage of the climatologically derived model over the mean model is real or an artifact of the different validation procedures: the dependence of the mean model on measured mass balances necessitates a cross validation, which implies that for the validation, information has to be withheld from the model, leading to a slight (and principally not determinable) decrease of the model's measured performance.

In comparison with the results from Marzeion et al. (2012), the performance of the mean model driven by CRU data is weaker than when driven with HISTALP data. This is to be expected, as the spatial resolution of the HISTALP data is six times that of the CRU TS 3.0 data. In this respect, we find the decrease of performance remarkably small (skill score in the Alps drops from 0.34 for the HISTALP data to 0.22 for the CRU TS 3.0 data, and correlation drops from 0.82 for the HISTALP data to 0.74 for the CRU TS 3.0 data). Similarly, it can be expected that the performance would increase if daily (instead of monthly) data were used for driving the model. Given the availability of reanalysis datasets, applying a higher temporal resolution is a possibility for future studies, but it has to be noted that the shorter time span over which daily data are available will also increase the demand on model performance, by raising the bar for achieving significant correlations.

Finally, we find it remarkably that - even though no information on measured mass balances enters the setup - the climatologically derived model outperforms the individually trained model when measured by correlation with observed mass balances. This seems counter-intuitive at first, but illustrates the versatility of the cross validation procedure, which detects the problems associated with parameter fitting when relatively few values (i.e., mass balance measurements) are available for training.

\section{Conclusions}

Qualitatively, our results closely resemble the findings of Nesje et al. (2000) and Reichert et al. (2001), who investigate the impact of NAO variability on selected glaciers in Scandinavia and the Alps. While the correlations values we find are 
less pronounced, we are able to show that there is a regional coherence in the mechanisms and impact of NAO variability on glacier mass balance, which allows for the classification of all European glaciers into four regions:

1. In southwestern Scandinavia, the variability of winter precipitation leads to a correlation between glacier mass balances and NAO, even though temperature anomalies work against this (in line with the findings of Reichert et al., 2001). There is a gradient within the region, with the correlation getting weaker (and even negative) towards the Northeast (in line with the results of Nesje et al., 2000).

2. In northern Scandinavia, temperature anomalies cause an anti-correlation between mass balance and NAO. The anti-correlation gets stronger towards the North.

3. In the western Alps, winter precipitation and temperature anomalies cause a (in our case, weak) anticorrelation between mass balances and NAO (in line with the results of Reichert et al., 2001).

4. In the eastern Alps, along the northern boundary of the Alps winter precipitation works towards a weak positive correlation between NAO and mass balances, but this effect is balanced by the effect of temperature. In the more central and southern parts, the lack of a precipitation signal leads to a weak anti-correlation between mass balances and NAO.

\section{Supplementary material related to this article is available online at: http://www.the-cryosphere.net/6/661/ 2012/tc-6-661-2012-supplement.pdf.}

Acknowledgements. This work was funded by the Austrian Science Fund (FWF): P22106-N21 and P22443-N21. We wish to thank Graham Cogley for providing the WGI-XF and global mass balance datasets, Regine Hock for discussions on the model set up, and four anonymous reviewers whose comments helped to improve the manuscript significantly. This is publication no. A383 from the Bjerknes Centre for Climate Research.

Edited by: J. O. Hagen

\section{References}

Auer, I., Böhm, R., Jurkovic, A., Lipa, W., Orlik, A., Potzmann, R., Schöner, W., Ungersböck, M., Matulla, C., Briffa, K., Jones, P., Efthymiadis, D., Brunetti, M., Nanni, T., Maugeri, M., Mercalli, L., Mestre, O., Moisselin, J.-M., Begert, M., Müller-Westermeier, G., Kveton, V., Bochnicek, O., Stastny, P., Lapin, M., Szalai, S., Szentimrey, T., Cegnar, T., Dolinar, M., Gajic-Capka, M., Zaninovic, K., Majstorovic, Z., and Nieplova, E.: HISTALP - historical instrumental climatological surface time series of the Greater Alpine Region, Int. J. Climatol., 27, 17-46, doi:10.1002/joc.1377, 2007.

Cogley, J. G.: Extended Format for the World Glacier Inventory, Tech. Rep. Trent Technical Note 2005-1, Department of Geography, Trent University, Peterborough, Ontario, Canada, revised September 2008, 2005.

Cogley, J. G.: Geodetic and direct mass-balance measurements: comparison and joint analysis, Ann. Glaciol., 50, 96-100, doi:10.3189/172756409787769744, 2009.

Hofer, M., Mölg, T., Marzeion, B., and Kaser, G.: Empiricalstatistical downscaling of reanalysis data to high-resolution air temperature and specific humidity above a glacier surface (Cordillera Blanca, Peru), J. Geophys. Res., 115, D12120, doi:10.1029/2009JD012556, 2010.

Hurrell, J.: Decadal trends in the North Atlantic Oscillation: regional temperatures and precipitation, Science, 269, 676-679, 1995a.

Hurrell, J. W.: NAO Index Data provided by the Climate Analysis Section, NCAR, Boulder, USA, available at: http://www. cgd.ucar.edu/cas/jhurrell/indices.html (last access: 28 December 2011), 1995b.

Hurrell, J. W., Kushnir, Y., Ottersen, G., and Visbeck, M. (Eds.): The North Atlantic oscillation: climatic significance and environmental impact, Geophysical Monograph, American Geophysical Union, Washington, DC, USA, 2003.

Huss, M., Hock, R., Bauder, A., and Funk, M.: 100-year mass changes in the Swiss Alps linked to the Atlantic Multidecadal Oscillation, Geophys. Res. Lett., 37, L10501, doi:10.1029/2010GL042616, 2010.

Jarosch, A. H., Anslow, F. S., and Clarke, G. K. C.: High-resolution precipitation and temperature downscaling for glacier models, Clim Dynam., 38, 391-409, doi:10.1007/s00382-010-0949-1, 2012.

Kaser, G., Grosshauser, M., and Marzeion, B.: Contribution potential of glaciers to water availability in different climate regimes, P. Natl. Acad. Sci. USA, 107, 20223-20227, doi:10.1073/pnas.1008162107, 2010.

Kuhn, M.: Micro-meteorological conditions for snow melt, J. Glaciol., 33, 24-26, 1987.

Marzeion, B., Hofer, M., Jarosch, A. H., Kaser, G., and Mölg, T.: A minimal model for reconstructing interannual mass balance variability of glaciers in the European Alps, The Cryosphere 6, 71-84, doi:10.5194/tc-6-71-2012, 2012.

Michaelsen, J.: Cross-validation in statistical climate forecast models, J. Appl. Meteorol., 26, 1589-1600, 1987.

Mitchell, T. D. and Jones, P. D.: An improved method of constructing a database of monthly climate observations and associated high-resolution grids, Int. J. Climatol., 25, 693-712, doi:10.1002/joc.1181, 2005.

Mölg, T. and Hardy, D. R.: Ablation and associated energy balance of a horizontal glacier surface on Kilimanjaro, J. Geophys. Res., 109, D16104, doi:10.1029/2003JD004338, 2004.

Nesje, A., Lie, Ø., and Dahl, S.: Is the North Atlantic Oscillation reflected in Scandinavian glacier mass balance records?, J. Quarternary Sci., 15, 587-601, 2000.

New, M., Lister, D., Hulme, M., and Makin, I.: A high-resolution dataset of surface climate over global land areas, Clim. Res., 21, 1-25, 2002. 
Oerlemans, J.: Analysis of a 3 year meteorological record from the ablation zone of Morteratschgletscher, Switzerland: energy and mass balance, J. Glaciol., 46, 571-579, doi:10.3189/172756500781832657, 2000.

Ohmura, A.: Physical basis for the temperature-based melt-index method, J. Appl. Meteorol., 40, 753-761, 2001.

Pohjola, V. A. and Rogers, J. C.: Atmospheric circulation and variations in Scandinavian glacier mass balance, Quarternary Res., 47, 29-36, doi:10.1006/qres.1996.1859, 1997.

Rasmussen, L. A. and Conway, H.: Influence of upper-air conditions on glaciers in Scandinavia, Ann. Glaciol., 42, 402-408, doi:10.3189/172756405781812727, 2005.

Reichert, B. K., Bengtsson, L., and Oerlemans, J.: Midlatitude forcing mechanisms for glacier mass balance investigated using general circulation models, J. Climate, 14, 3767-3784, 2001.

Scherrer, S., Appenzeller, C., and Laternser, M.: Trends in Swiss Alpine snow days: the role of local- and largescale climate variability, Geophys. Res. Lett., 31, L13215, doi:10.1029/2004GL020255, 2004.

Sicart, J., Hock, R., and Six, D.: Glacier melt, air temperature, and energy balance in different climates: the Bolivian Tropics, the French Alps, and Northern Sweden, J. Geophys. Res., 113, D24113, doi:10.1029/2008JD010406, 2008.
Six, D., Reynaud, L., and Letréguilly, A.: Bilans de masse des glaciers alpins et scandinaves, leurs relations avec l'oscillation du climat de l'Atlantique nord: Alpine and Scandinavian glaciers mass balances, their relations with the North Atlantic Oscillation, C.R. Acad. Sci. II A, 333, 693-698, 2001.

Steiner, D., Pauling, A., Nussbaumer, S., Nesje, A., Luterbacher, J., Wanner, H., and Zumbühl, H.: Sensitivity of European glaciers to precipitation and temperature - two case studies, Climatic Change, 90, 413-441, 2008.

Visbeck, M. H., Hurrell, J. W., Polvani, L., and Cullen, H. M.: The North Atlantic Oscillation: past, present, and future, P. Natl. Acad. Sci. USA, 98, 12876-12877, 2001.

Wanner, H., Brönnimann, S., Casty, C., Gyalistras, D., Luterbacher, J., Schmutz, C., Stephenson, D. B., and Xoplaki, E. North Atlantic Oscillation - concepts and studies, Surv. Geophys., 22, 321-381, 2001.

WGMS (World Glacier Monitoring Service) and NSIDC (National Snow and Ice Data Center): World Glacier Inventory. Compiled and made available by the WGMS, Zurich, Switzerland, and the NSIDC, Boulder CO, USA, available at: http://nsidc.org/data/ glacier_inventory/index.html (last access: 28 December 2011), 1989. 